Supporting Information for

\title{
Assessment of Bioavailability of Biochar-Sorbed Tetracycline to Escherichia coli for Activation of Antibiotic Resistance Genes
}

\author{
Bingyu Wang, ${ }^{\dagger}, \stackrel{\star}{\S}$ Yingjie Zhang, ${ }^{\dagger}$ Dongqiang Zhu, ${ }^{\dagger, \#}$ and $\mathrm{Hui}_{\mathrm{Li}}{ }^{\dagger}, *$
}

† Department of Plant, Soil and Microbial Sciences, Michigan State University, East Lansing,

Michigan 48824, United States

‡ State Key Laboratory of Pollution Control and Resource Reuse, School of the Environment,

Nanjing University, Nanjing, Jiangsu 210023, China

\# School of Urban and Environmental Sciences, Peking University, Beijing 100871, China

$\S$ Jiangsu Key Laboratory of Chemical Pollution Control and Resources Reuse, School of

Environmental and Biological Engineering, Nanjing University of Science and Technology,

Nanjing, Jiangsu 210094, China

Number of pages: 10; Number of Figures: 5; Number of Tables: 2

* Corresponding author: Tel: +1-517-353-0151; Fax: +1-517-355-0270; Email: lihui@msu.edu. 


\section{Characterization of Biochars}

The elemental analysis of BCs was performed using a Vario EL cube (Elementar, Germany). Specifically, the ground BC samples were combusted at $950{ }^{\circ} \mathrm{C}$, and then lowered to $550{ }^{\circ} \mathrm{C}$ to determine $\mathrm{C}, \mathrm{N}$, and $\mathrm{H}$ contents. Another set of samples was pyrolytically decomposed at $1150{ }^{\circ} \mathrm{C}$ to determine $\mathrm{O}$ content. XPS measurement was carried out using a PHI 5000 Versaprobe (ULVAC-PHI, Japan) with a monochromatized Al Ka radiation (hv=1486.6 eV). Quantification of mineral compositions in the BC samples was conducted by a Thermo Fisher ARL 9800XP+ X-ray fluorescence spectrometer (XRF). Prior to the XRF analysis, the BC samples were combusted at $500{ }^{\circ} \mathrm{C}$ for $30 \mathrm{~min}$, then increased to $800{ }^{\circ} \mathrm{C}$ and held at the temperature for $1 \mathrm{~h}$ to oxidize the organic fractions in the sample. During this process, all inorganic elements were oxidized to their highest oxidation state, which improved the accuracy of XRF analysis. The BC powders were laminated to be enclosed in plastic wraps using an electric laminating machine under $20 \mathrm{MPa}$ pressure. The samples were analyzed using the UQ method of the XRF under vacuum with an effective area of $2.5 \mathrm{~cm}$-diameter circle. X-ray diffraction (XRD) patterns of $\mathrm{BCs}$ were recorded using a Rigaku D/max-RA powder diffractometer (Tokyo, Japan) equipped with $\mathrm{Cu} \mathrm{K \alpha}$ radiation at $40 \mathrm{kV}$ and $200 \mathrm{~mA}$. The diffraction angles ranged from 10 to $70^{\circ}$ with a scan speed of $8 \% \mathrm{~min}$. Prior to the XRD analysis, BC samples were ground using a mortar, and pressed into sample holder evenly with a glass slide. Raman spectra of the BCs were recorded using a LabRAM-HR Raman spectroscopy with a laser excitation wavelength of $514 \mathrm{~nm}$, and the Raman shift ranged from 800 to $1850 \mathrm{~cm}^{-1}$. Specific surface areas and porosity of BCs were estimated based on $\mathrm{N}_{2}$ sorption/desorption isotherms measured at $-196^{\circ} \mathrm{C}(77 \mathrm{~K})$ using an ASAP 2020 Accelerated Surface Area and Porosimetry System (Norcross, GA, USA). Prior to the $\mathrm{N}_{2}$ sorption, $\mathrm{BCs}$ were degassed at $300^{\circ} \mathrm{C}$ under vacuum for $3 \mathrm{~h}$. This activation procedure could completely remove the sorbed water residues. The holding time at each sorption/desorption step was set at $30 \mathrm{sec}$ after $\mathrm{N}_{2}$ reached the sorption/desorption equilibration.

\section{Plate-Counting Method}

LB agar medium was prepared by dissolving $15 \mathrm{~g}$ of agar, $10.45 \mathrm{~g}$ of MOPS, $10.0 \mathrm{~g}$ of tryptone, $5.0 \mathrm{~g}$ of yeast extracts and $0.5 \mathrm{~g}$ of $\mathrm{NaCl}$ in $1.0 \mathrm{~L}$ of $0.22 \mu \mathrm{m}$ membrane-filtered Milli-Q water. The $\mathrm{pH}$ of media was adjusted to 7.0 with $2.0 \mathrm{M} \mathrm{NaOH}$, and it was autoclaved at $121{ }^{\circ} \mathrm{C}$ 
for $30 \mathrm{~min}$. LB agar plates were prepared by pouring $10 \mathrm{~mL}$ of hot $\mathrm{LB}$ agar medium amended with $100 \mathrm{mg} \mathrm{L}^{-1}$ ampicillin on sterilized petri dish and cooled down for $30 \mathrm{~min}$. Then $100 \mu \mathrm{L}$ of the detached bacterial suspension (described above) underwent a $10^{6}$-fold serial dilution and was spread on the LB agar plates. The inoculated plates were incubated at $30 \pm 0.2{ }^{\circ} \mathrm{C}$ for $24 \mathrm{~h}$ and the number of colony-forming units (CFU) was counted on each plate. All samples were prepared in triplicate. 
Table S1. Elemental Composition, Atomic Ratio and Mineral Compositions (on a Dry Weight Basis) of Biochars

\begin{tabular}{|c|c|c|c|c|c|c|c|c|c|c|c|c|}
\hline \multirow{2}{*}{$\begin{array}{c}\text { Biochar } \\
\text { Sorbents }\end{array}$} & \multicolumn{4}{|c|}{ Elemental Composition ${ }^{a}$} & \multicolumn{3}{|c|}{ Atomic Ratio $^{b}$} & \multicolumn{5}{|c|}{ Mineral Composition $(\%)^{c}$} \\
\hline & $\mathrm{C} \%$ & H\% & $\mathbf{N \%}$ & $0 \%$ & $\mathbf{H} / \mathbf{C}$ & $\mathrm{O} / \mathrm{C}$ & $(\mathrm{O}+\mathrm{N}) / \mathrm{C}$ & $\mathrm{SiO}_{2}$ & MgO & $\mathbf{C a O}$ & $\mathrm{Al}_{2} \mathrm{O}_{3}$ & $\mathrm{Fe}_{2} \mathrm{O}_{3}$ \\
\hline Rice400 & 56.6 & 3.1 & 0.1 & 23.6 & 0.054 & 0.42 & 0.42 & 0.37 & 0.89 & 0.14 & 0.090 & 0.060 \\
\hline Rice500 & 77.4 & 2.7 & 0.1 & 17.6 & 0.034 & 0.23 & 0.23 & 0.25 & 0.27 & 0.075 & 0.011 & 0.023 \\
\hline Wheat 400 & 65.1 & 2.8 & 0.2 & 29.8 & 0.043 & 0.46 & 0.46 & 0.008 & 0.058 & 0.013 & 0.004 & 0.001 \\
\hline Wheat500 & 74.5 & 2.6 & 0.1 & 21.1 & 0.035 & 0.28 & 0.29 & 0.021 & 0.27 & 0.079 & 0.007 & 0.002 \\
\hline Maize400 & 65.5 & 3.5 & 0.1 & 27.8 & 0.054 & 0.43 & 0.43 & 0.011 & 0.43 & 0.06 & 0.005 & 0.001 \\
\hline Maize500 & 72.8 & 2.8 & 0.1 & 23.2 & 0.038 & 0.32 & 0.32 & 0.026 & 0.55 & 0.10 & 0.004 & 0.001 \\
\hline Bean400 & 68.9 & 3.2 & 0.1 & 22.8 & 0.047 & 0.33 & 0.33 & 0.013 & 0.63 & 0.16 & 0.016 & 0.003 \\
\hline Bean500 & 71.5 & 2.6 & 0.1 & 19.4 & 0.036 & 0.27 & 0.27 & 0.036 & 1.6 & 0.94 & 0.03 & 0.01 \\
\hline
\end{tabular}

${ }^{a}$ Determined by elemental analysis using the combustion method.

${ }^{b} \mathrm{H} / \mathrm{C}$ : atomic ratio of hydrogen to carbon. $\mathrm{O} / \mathrm{C}$ : atomic ratio of oxygen to carbon. $(\mathrm{O}+\mathrm{N}) / \mathrm{C}$ : atomic ratio of the sum of nitrogen and oxygen to carbon.

${ }^{\mathrm{c}}$ Determined by X-ray fluorescence (XRF). 
Table S2. Summary of Freundlich Model Parameters ( $K_{\mathrm{F}}$ and $\left.n\right)$, and the Percent of Desorbed Tetracycline from Biochars

\begin{tabular}{|c|c|c|c|c|c|c|c|}
\hline \multirow{2}{*}{ Biochar } & \multicolumn{3}{|c|}{ Sorption } & \multicolumn{3}{|c|}{ Desorption } & \multirow{2}{*}{$\left(q_{\text {sorb }}-q_{\text {desorb }}\right) / q_{\text {sorb }}$} \\
\hline & $\begin{array}{c}K F \\
\left(10^{3} \times \mu g^{1-n} L^{n} k^{-1}\right)\end{array}$ & $n_{\text {sorb }}$ & $R^{2}$ & $\begin{array}{c}K F \\
\left(10^{3} \times \mu g^{1-n} L^{n}{k g^{-1}}^{-1}\right)\end{array}$ & $n_{\text {desorb }}$ & $R^{2}$ & \\
\hline Rice400 & $87 \pm 12$ & $0.57 \pm 0.03$ & 0.97 & $25 \pm 3$ & $0.73 \pm 0.03$ & 0.99 & $19.1 \pm 2.7 \%$ \\
\hline Rice500 & $211 \pm 27$ & $1.25 \pm 0.09$ & 0.94 & $102 \pm 14$ & $0.75 \pm 0.04$ & 0.97 & $4.0 \pm 1.0 \%$ \\
\hline Wheat 400 & $169 \pm 27$ & $0.50 \pm 0.04$ & 0.91 & $33 \pm 3$ & $0.75 \pm 0.02$ & 0.99 & $13.7 \pm 1.8 \%$ \\
\hline Wheat500 & $185 \pm 15$ & $1.31 \pm 0.06$ & 0.98 & $72 \pm 10$ & $0.82 \pm 0.04$ & 0.97 & $4.9 \pm 0.8 \%$ \\
\hline Maize400 & $99 \pm 8$ & $0.51 \pm 0.02$ & 0.99 & $29 \pm 4$ & $0.75 \pm 0.03$ & 0.98 & $15.4 \pm 2.1 \%$ \\
\hline Maize500 & $142 \pm 20$ & $1.08 \pm 0.07$ & 0.96 & $77 \pm 8$ & $0.74 \pm 0.03$ & 0.98 & $5.5 \pm 1.0 \%$ \\
\hline Bean400 & $23 \pm 5$ & $0.50 \pm 0.04$ & 0.96 & $6 \pm 3$ & $0.78 \pm 0.01$ & 0.87 & $44.5 \pm 6.0 \%$ \\
\hline Bean500 & $64 \pm 15$ & $0.77 \pm 0.06$ & 0.92 & $36 \pm 5$ & $0.84 \pm 0.04$ & 0.98 & $9.4 \pm 1.7 \%$ \\
\hline
\end{tabular}



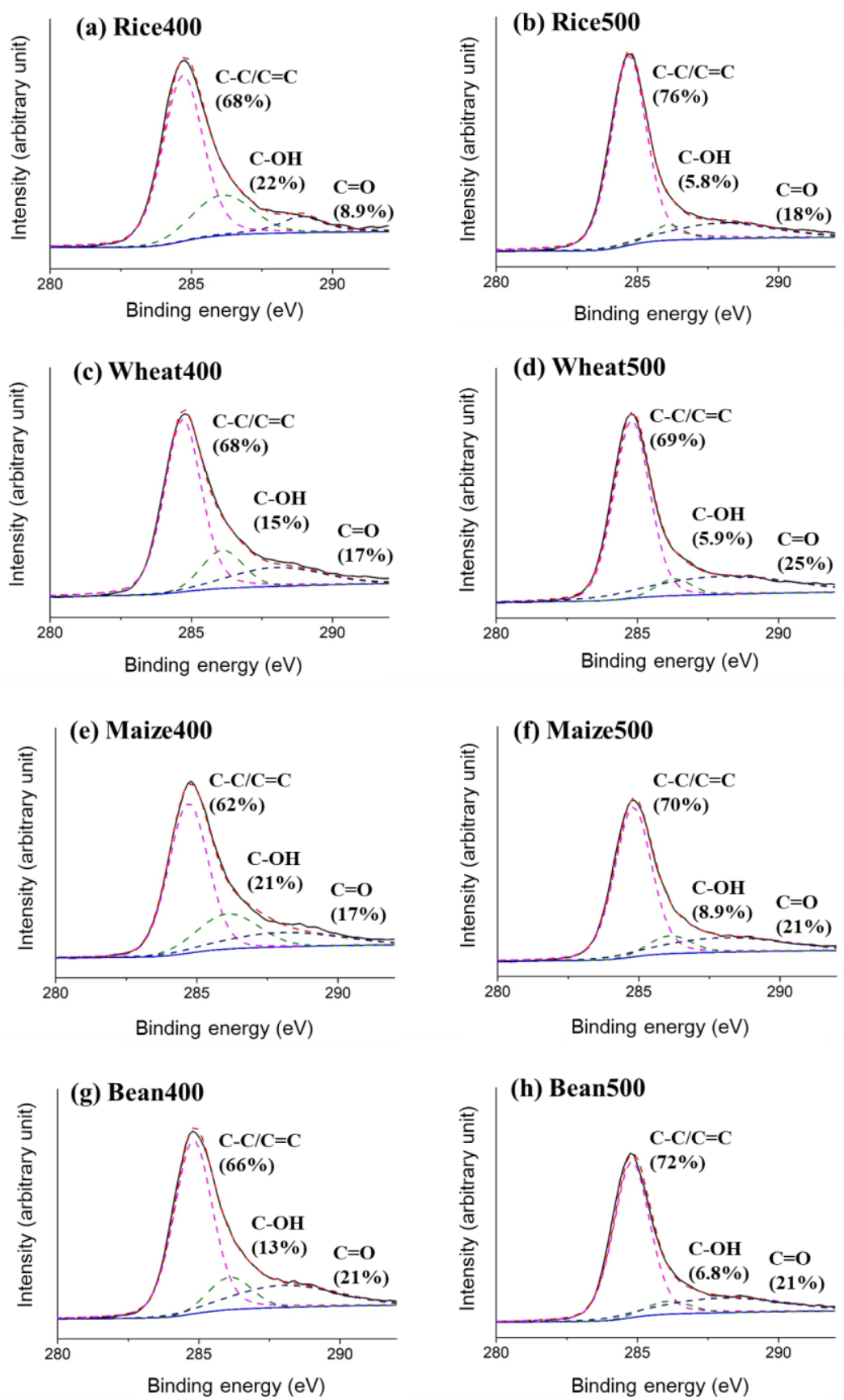

Figure S1. C1s X-ray photoelectron spectroscopy (XPS) spectra of BC sorbents. The peaks with binding energy of $284.7,286.1$, and $288.0 \mathrm{eV}$ are assigned to aromatic carbons $(\mathrm{C}-\mathrm{C} / \mathrm{C}=\mathrm{C})$, hydroxyl carbon $(\mathrm{C}-\mathrm{OH})$, and carbonyl carbon $(\mathrm{C}=\mathrm{O})$, respectively. The deconvolution of XPS spectra was conducted using XPSPEAK (version 4.1) software. Shirley-type background was carried out to correct background noise and adjusted the slope of Shirley and Linear curve for an appropriate baseline. Four parameters, peak position, width at half maxima, area and percent of Lorentzian-Gaussian, were optimized to achieve the best fitting of the overlapping peak to the original peak. The relative $\mathrm{C}$ content of each functional group was calculated based on the fitted peak area. 

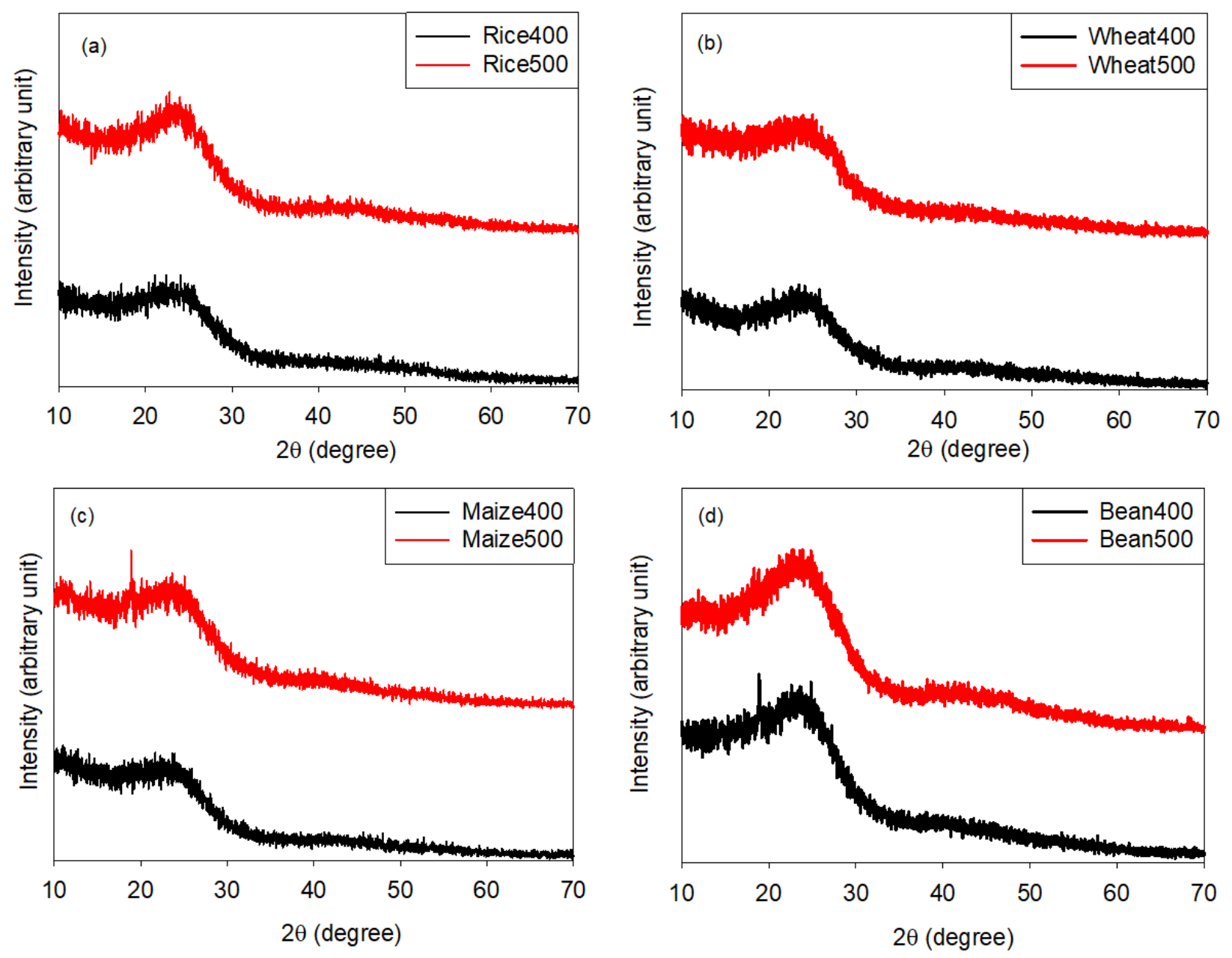

Figure S2. X-ray diffraction (XRD) patterns for BC sorbents of (a) Rice400 and Rice500, (b) Wheat400 and Wheat500, (c) Maize400 and Maize500, and (D) Bean400 and Bean500. XRD patterns were recorded with the diffraction angles ranging from 10 to $70^{\circ}$ using a Rigaku D/max-RA powder diffractometer with $\mathrm{Cu} \mathrm{K \alpha}$ radiation. 

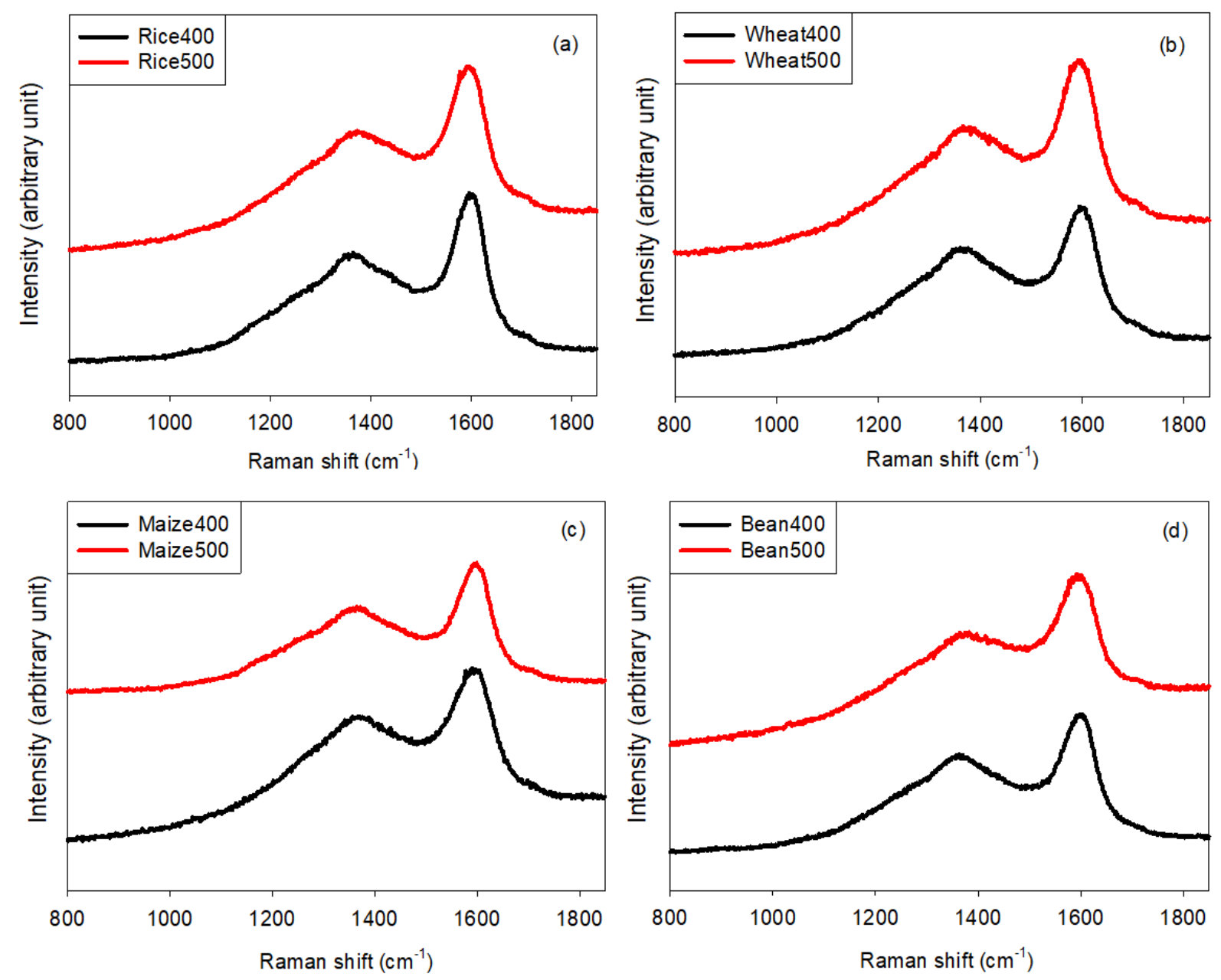

Figure S3. Raman spectra for BC sorbents of (a) Rice400 and Rice500, (b) Wheat 400 and Wheat500, (c) Maize400 and Maize500, and (D) Bean400 and Bean500. Raman spectra were recorded on a LabRAM-HR Raman spectrometer with a laser excitation wavelength of $514 \mathrm{~nm}$. 


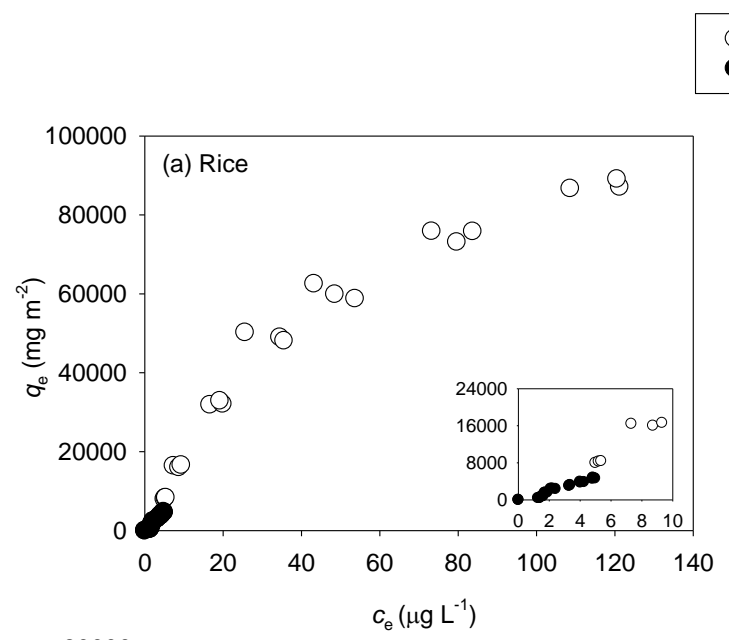

BC400
BC500
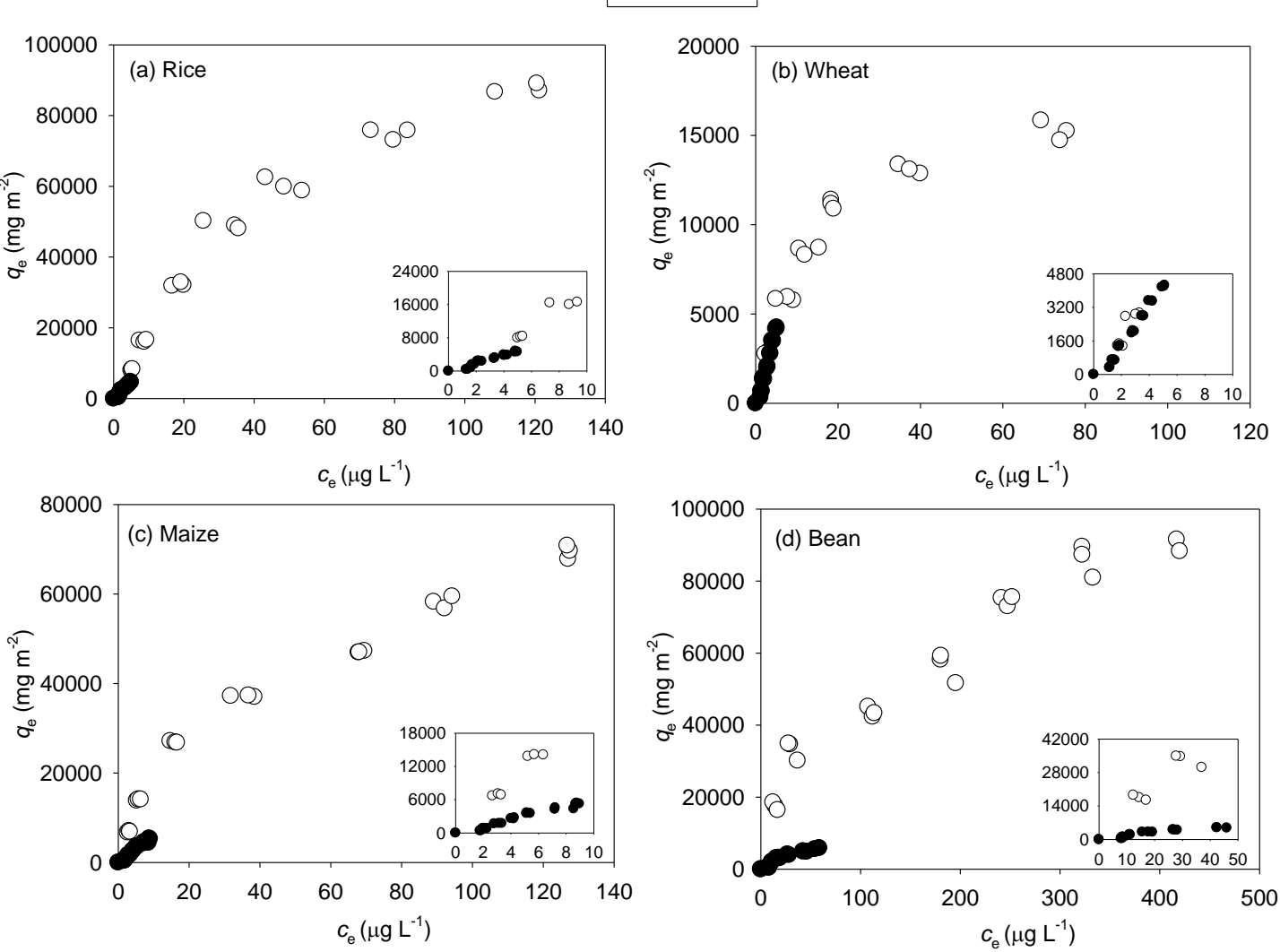

Figure S4. Tetracycline sorption plotted as sorbed concentration normalized to surface area $\left(q_{\mathrm{e}}\right)$ vs. aqueous-phase concentration $\left(C_{\mathrm{e}}\right)$ at equilibrium. (a) rice, (b) wheat, (c) maize, and (d) bean BCs. 

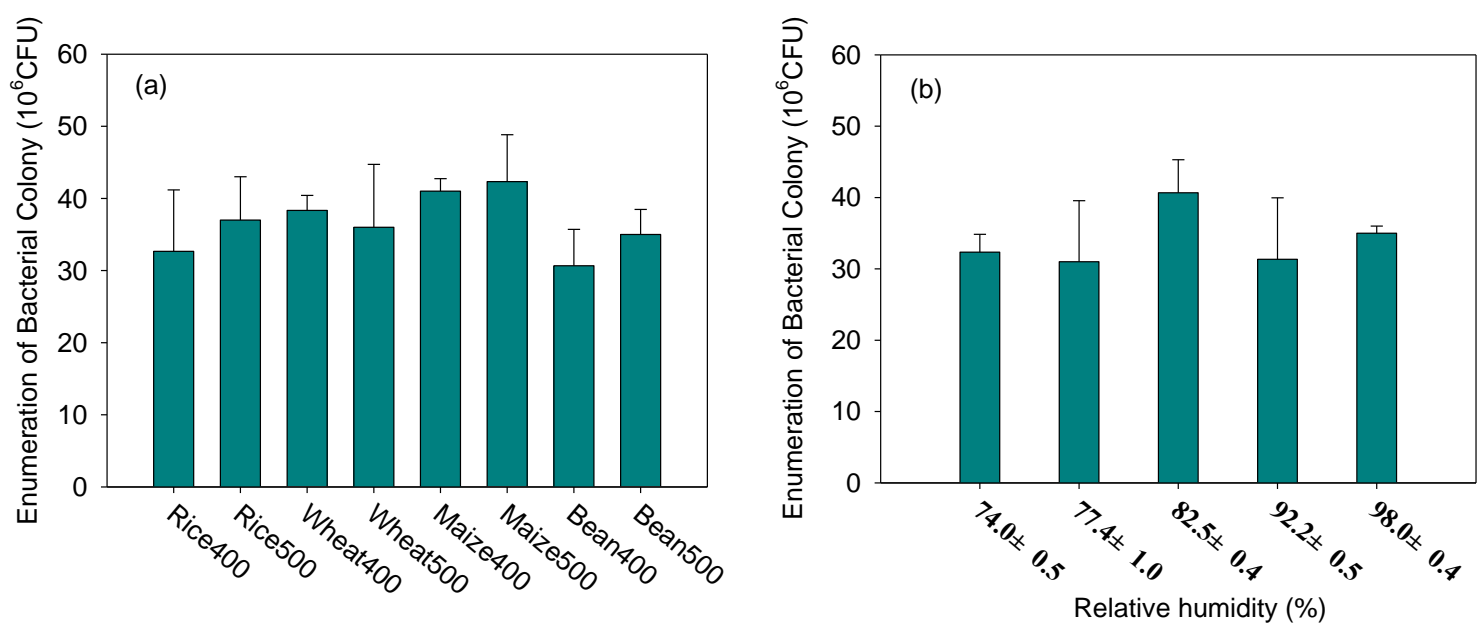

Figure S5. Enumeration of bacterial colonies growing on (a) different types of BCs under the ambient relative humidity of $98 \%$, and (b) Rice400 under varying levels of relative humidity. Error bars represent the standard deviations $(n=3)$. 